\title{
Evaluation of the Cohesion of Crumb Rubber Modified Bitumens by Means of UCL Method
}

\author{
Páez Dueñas A. ${ }^{1}$ - Pérez Jiménez F. ${ }^{2}$ - Miró Recasens R. ${ }^{2}$ \\ ${ }^{1}$ Repsol YPF. \\ Carretera de Extremadura, km 18. 28931 Móstoles. Spain. \\ apaezd@repsolypf.com \\ ${ }^{2}$ Technical University of Catalonia. \\ Jordi Girona, 1-3, Módulo B-1. 08034 Barcelona, Spain. \\ edmundo.perez@upc.edu \\ r.miro@upc.edu
}

\begin{abstract}
The aim of this paper is to study the influence of crumb rubber on the improvement of cohesion provided by bitumen. The UCL Method is a procedure for binder characterization based on the evaluation of the degree of cohesion provided by a set amount of binder to an aggregate of a set grading (standard mixture). This method can be used to evaluate both, the dry and the wet adding procedures. The results obtained show that the wet procedure presents clear advantages over the dry procedure with and without digestion, especially when the binders are manufactured by microscopic dispersion.
\end{abstract}




\section{Introduction}

A significant problem in western countries is the existence of a long stockpile of used rubber. One of the proposed solutions has been its use as component of asphalt mixtures.

It has been established that crumb rubber improve the rheological properties of asphalt (Van Kirk et al., 2000). Due to this fact, crumb rubber has been applied since sixties (Morris et al., 1973). The use of crumb rubber modified asphalt binders in pavement applications include crack sealants; binders for chip seals, interlayer and hot-mix asphalts; and membranes (Epps et al., 1994). The states of Florida, California and Arizona use crumb rubber in asphalt cements in contents varying from 5 to $30 \%$, in both dense and open graded asphalt, especially in surface treatments (Hicks et al., 1995).

In the past decades, many researchers have continuously researched crumb rubber asphalt. The major efforts have been made in the studies of it behavior in classical test, for example Marshall Test or in its contribution of increase of Asphalt Modulus or improvement of fatigue performance (Leto et al., 2000).

However there is a lack of studies about one of the most important properties that asphalt rubber impart to the mixes, like is cohesion.

\section{Asphalt Mixture Cohesion}

By using the Cantabrian Test, developed in Spain in 1979, all the factors related to the cohesion of the mixture, and particularly to the toughness of the binder are revealed (Pérez Jiménez et al., 1990). The Cantabrian Test consists on the introduction of a porous mixture specimen (a Marshall type, $\phi=16 \mathrm{~cm}$; h=5-6 cm) inside Los Angeles drum and to submit it to 300 revolutions without any kind of abrasive charge. Due to the specimen impact to the drum walls and to the abrasive effect of the friction to these walls, the aggregates at the specimen surface are lost. On each turn of the drum, the breaking energy applied to the specimen is consumed on the elastic and plastic deformation of the specimen, as well as on the fracture of the aggregates unions. The bigger the binder ability to absorb this energy through deforming (elastic and plastically) the lower the loss of particles will be. In the test, the calculation of lost particles is determined by the following expression:

$$
C L=\frac{W_{\text {initial }}-W_{\text {final }}}{W_{\text {initial }}} \times 100
$$

where CL is the Cantabrian losses $(\%), \mathrm{W}_{\text {initial }}$ is the initial weight, in grams, and $\mathrm{W}_{\text {final }}$ is the final weight, in grams. 
Nowadays the Cantabrian test is included in the majority of the world standards (CEN, ASTM) and it is used for the porous asphalt mixtures and stone mastic asphalt design (Pérez Jiménez et al., 1990).

Since 1989, the Cantabrian test has been applied to evaluate the ability of the binder to impart cohesion to the asphalt mixtures. As a result of this research the UCL Method (Universal Method for Binder Characterization) was developed (Pérez Jiménez et al., 1993). This method, as it has already been explained, is based on the determination of the cohesion ability given to a standard mixture by a fixed amount of binder, and is also used to study the influence in the cohesion of the mixture of temperature. The results obtained show high sensitivity, repeatability and reproducibility of the test (Pérez Jiménez et al., 1997), which allows an easy graphical comparison of the behavior of all binder types, both plain and modified binders. The experience of near twenty years of application is that one of the most powerful characteristic of the UCL method is it ability of making comparisons between binders in terms of cohesion.

The UCL method can also be used to evaluate the filler effect of bituminous mastics (Pérez Jiménez et al., 2008). The filler is an essential element of the bituminous mixtures because it is the mixture component which is most intimated mixed with the binder, modifying both its rehology and its behavior. Usually, the filler and binder characterization are independent and do not take into account that the crossing influence of their mixture. The UCL method allows evaluating the behaviour of the binder-filler system (mastic), because it can evaluate both the cohesion ability of a binder in a standard mixture, and the effect of an established amount of mastic in the same standard mixture. In this way, the filler influence to fill the mixture voids and to modify the susceptibility and cohesion ability of the binder can be measured. The UCL method has been recently applied to analyze the binders modified with crumb rubber.

\subsection{UCL method}

The UCL method is based, as it has been explained before, on the evaluation of the cohesion given by a fixed amount of binder to a fixed grading of aggregates (standard mixture), by means the Cantabrian test. From the beginning of the method, the grading used was basically composed of a high percentage of coarse particles and by a little amount of sand without fines. I.e., the objective was to give cohesion to particles of the same size with a fixed amount of binder. The function of the sand is to fill the mixture and given it a better resistance to disgregation as it is a sand without fines, there is no mastic formation in the mixture so, the thin film which covers the aggregates is only composed of binder. After testing many kinds of grading, a standard grading was fixed, consisting of $80 \% 2.5 / 5 \mathrm{~mm}$ aggregate and $20 \% 0.63 / 2.5 \mathrm{~mm}$ aggregate. This decision was taken because it was the grading which had the best repeatability and reproducibility. 
The Los Angeles abrasion of the aggregates used in the mixtures must be lower than 20 so that the aggregates do not break during the specimen compaction and manufacture. A bitumen content of $4.5 \%$ of the aggregate yields a mixture voids content of $27 \pm 1 \%$.

The performance curve is one of the main results obtained when the UCL Method is applied to the bituminous binders characterization. Testing the specimens under different temperature conditions it is observed that when the temperature is lower than $15-25^{\circ} \mathrm{C}$ (depending on the binder type and on its penetration) there is a process in which the binder became fragile and there is a toughness loss of the binder, increasing the Cantabrian losses. When the temperature is higher than these values, the binder losses its consistency and its ability to maintain the aggregates together decreases. As a consequence the losses increase again.

The performance curve shows the performance of the binder as a cohesive material in a wide range of temperatures. The lower the performance curve and its slope when varying the temperature better will be the expected behavior of the binder. Figure 1 shows the performance curves of different types of binders: asphalt cement with different penetration grades (from B-10/20 to B-150/200), and polymeric modified binders for SMA mixtures and porous asphalt mixtures.

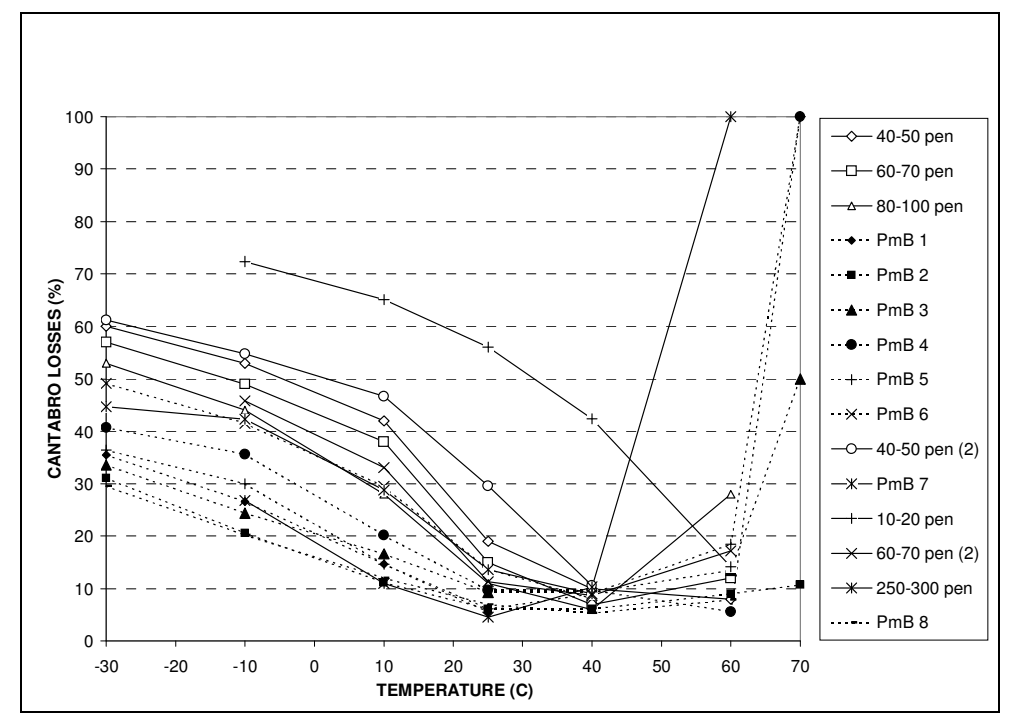

Figure 1. UCL Performance curves for different types of binders 
The performance curves for the modified binders are clearly located at the bottom of the figure, with lower losses and flatter curves. If we observe the conventional asphalt binders, their curves depend on their losses between $10-25{ }^{\circ} \mathrm{C}$. I.e., at low temperatures the harder bitumen is the ones with higher losses and vice versa at low temperatures.

The test has a great sensitivity when the binders studied have the same penetration but different penetration index (Pérez Jiménez et al., 1993). The lower the penetration index, the higher the slope of the performance curve. This sensitivity of the test to appreciate these variations of the performance is linked to the high repeatability and reproducibility of the method.

The UCL Method can be also used to evaluate the filler potential to modify the bitumen behavior in the mixture. The filler is the finest mineral component added to the asphalt mixture. Due to the little size of the filler particles (less than 0.063 or $0.080 \mathrm{~mm}$ ) during the mixture manufacture the filler is located inside the bitumen film, modifying and changing its performance. The filler has the ability to modify the bitumen viscosity, increasing its breaking resistance and decreasing its ductility. This effect depends on the fineness of the filler, on its nature and on the volumetric ratio filler/binder.

Analyzing the filler effect on the cohesion ability of the binder the procedure developed by Professor Ruiz from Argentina has been considered. In this procedure, the maximum amount of filler which can be added to fill the binder film is determined by means of a sedimentation test, assuring that every filler particle is covered by the binder film. Regarding this maximum concentration, called critical concentration (Cs), the effect of the filler quantity and its nature on the cohesion ability of the binder has been analyzed. By means of the UCL Method, using its standard grading and a $4.5 \%$ of bitumen B-60/70, the effect of different kind of fillers has been compared. Figure 2 shows the results of the losses in Los Àngeles drum at $25^{\circ} \mathrm{C}$ and 300 revolutions when specimens of the standard mixture are tested. Different filler concentrations and different filler types have been added to the tested mixtures.

It can be observed in the figure that the filler nature has little effect on the results up to volumetric concentrations of 1.0. It is also observed that when using filler volumetric concentrations above 1.5 there is an important stiffness and fragilization of the mastic which produces a rapid disgregation of the mixture. This shows that although the filler effect is good to increase the binder viscosity and the resistance to mixture deformation, an excess of filler produces a decrease of its cohesion ability.

The results of these tests show the great capacity of the UCL Method to analyze the crumb rubber effect, since in some cases it has been introduced using the dry procedure (as if it were a filler which interacts with the binder), while in other cases it has been firstly mixed with the bitumen, obtaining a modified binder.

The performance curves of the binders modified with the crumb rubber obtained by both ways, dry and wet, allow to compare between both procedures and to compare them with the not modified bitumens. 


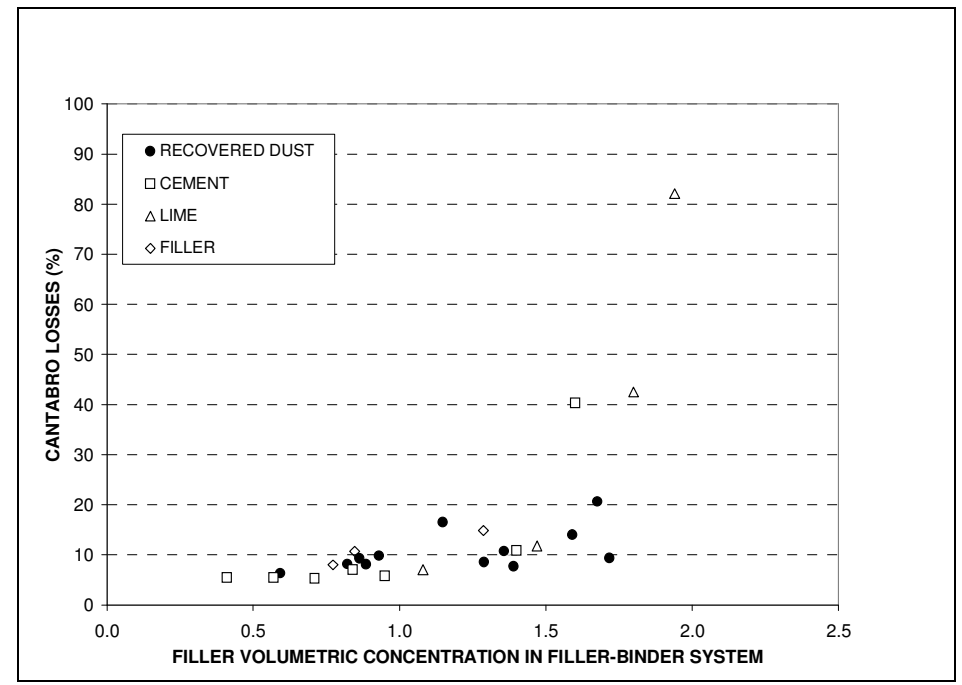

Figure 2. Variation of Cántabro losses with filler volumetric concentration

\section{Crumb Rubber Effect Analysis}

\subsection{Dry Procedure}

The work has been conducted with a conventional binder, B-60/70 (pen: 68 , R\&B: $48.8^{\circ} \mathrm{C}$, PI: -0.74). Two different sizes of crumb rubber have been added to this binder, P0.4 and P08 ( 0.4 and $0.8 \mathrm{~mm}$ respectively), and also a SBS powder. In the three cases two concentrations have been studied. The asphalt mixtures manufactured with crumb rubber and SBS have been compared with a mixture manufactured with a $\mathrm{CaCo}_{3}$ filler and another one which didn't have filler. Table 1 summarizes the formulations of the different mixtures tested using the UCL Method.

\begin{tabular}{|c|c|c|c|c|c|c|c|c|}
\hline SERIES & 1 & 2 & 3 & 4 & 5 & 6 & 7 & 8 \\
\hline TYPE OF FILLER $^{\prime}$ & - & $\mathrm{P} 0.4$ & $\mathrm{P} 0.8$ & $\mathrm{P} 0.4$ & $\mathrm{P} 0.8$ & $\mathrm{CaCO}_{3}$ & $\mathrm{SBS}$ & $\mathrm{SBS}$ \\
\hline $\mathbf{C}_{\mathbf{v}} \mathbf{C}_{\mathbf{s}}$ & 0 & 0.5 & 0.5 & 1.0 & 1.0 & 1.0 & $(*)$ & $(*)$ \\
\hline AGGREGATES WEIGHT (g) & 900 & 900 & 900 & 900 & 900 & 900 & 900 & 900 \\
\hline BINDER WEIGHT (g) & 40.5 & 40.5 & 40.5 & 40.5 & 40.5 & 40.5 & 40.5 & 40.5 \\
\hline FILLER WEIGHT (g) & 0 & 4.80 & 3.71 & 10.7 & 8.03 & 46.69 & 3.71 & 8.03 \\
\hline
\end{tabular}

(*) It was not possible to calculate this value

Table 1. Formulations of the mixtures manufactured using the dry procedure 
Figure 3 shows the performance curves obtained of the 8 formulas tested. They also summarize the voids of these formulas. First of all it is observed that the addition of mineral filler implies a reduction of the voids content in the mixtures, while the addition of crumb rubber increases them. The mixture without filler has a $27.3 \%$ of voids, while the same mixture manufactured with filler has a $24.6 \%$ of voids content for the volumetric ratio of $\mathrm{Cv} / \mathrm{Cs}=1$. For the same volumetric ratio the mixture manufactured with crumb rubber P0.4, has a $27.7 \%$ of voids and with the P0.8, a $27.2 \%$. On the contrary, the SBS addition hardly modifies the void content. In the case of the mineral filler, the powder seems to be incorporated inside the bitumen film without avoiding the mixture compaction and filling the voids between the coarser particles. On the contrary, in the case of the crumb rubber it is as if it a thicker film covering the particles has been formed making difficult their cohesion.

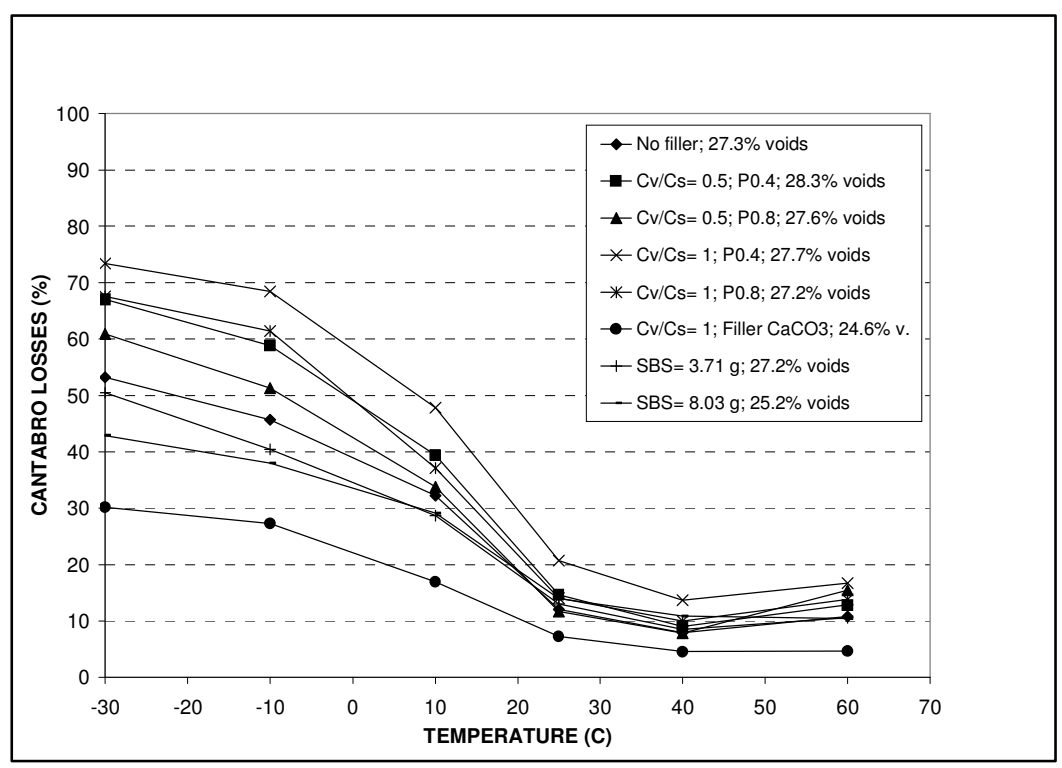

Figure 3. UCL Performance curves. Dry procedure

The voids calculation has been determined starting from the volume of each of the components of the different formulas and also, considering the added weight and the specific weight of each component.

The performance curves of the mastics are in concordance to the porosity of the tested formulas. The better performance was observed with the mixture 
manufactured with mineral filler. The worst was the one which contained the crumb rubber $\mathrm{P} 0.4$ with the volumetric ratio $\mathrm{Cv} / \mathrm{Cs}=1$. It looks as if the mastic created by the crumb rubber was less tough and consistent than the original binder or the one obtained adding SBS or mineral filler.

\subsection{Dry procedure with digestion}

The objective of this test was to study how changes in the process and the manufacture time could modify the results. The mixture has been subjected to a digestion process before its compaction. In this process the mixture is introduced in an oven at $165^{\circ} \mathrm{C}$ for three different periods of time in each of the three cases studied (0, 1 and 2 hours). The crumb rubber added was the P0.8. The ratio filler-binder considered was $\mathrm{Cv} / \mathrm{Cs}=0,5$, and the test have been carried out with the same binder studied in the dry procedure. The performance curves have been plotted in Figure 4. This figure shows that the digestion time has a positive influence in the binder cohesion, which increases its disgregation resistance with the digestion time. The compacity though remains almost the same.

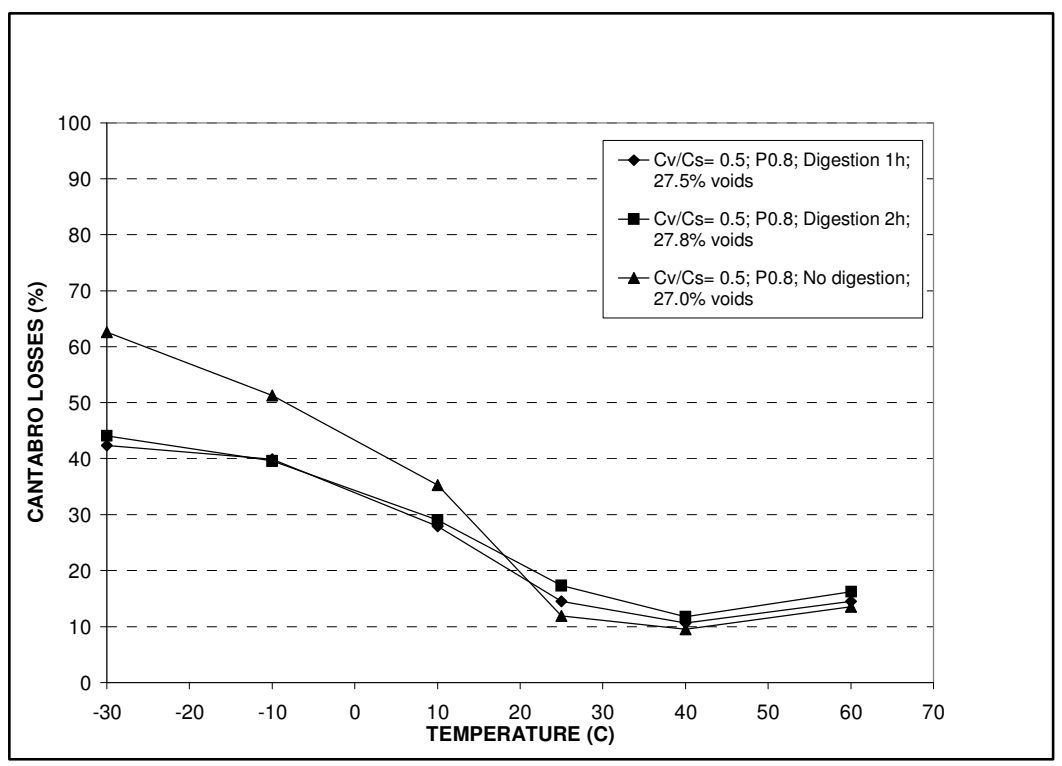

Figure 4. UCL Performance curves. Dry procedure with digestion 


\subsection{Wet procedure}

For the wet procedure two kind of methods have been used to manufacture the mixtures, in suspension (manufacture with the kneading machine in UPC lab) and under microscopic dispersion (manufacture in Repsol-YPF laboratory). For the suspension manufacture the same binder used in the dry procedure (B-60/70) has been used. Different percentages of crumb rubber P0.8 have been added to this binder: 10,15 and $20 \%$. The crumb rubber addition to the binder has been carried out at $180^{\circ} \mathrm{C}$, and the new binder obtained has been called $\mathrm{B} 2$. The binder manufactured under microscopic dispersion has been called B3.

Figure 5 shows the performance curves of the both binders. The differences in porosity are relatively small and have little effect on the observed losses, since at $25^{\circ} \mathrm{C}$ the losses for all the bitumens are very similar. On the other side, at low temperatures, the different fragility of the bitumens is shown. It can be observed that this manufacture process has a positive effect which is higher with higher additions of crumb rubber. The binder B3 manufactured by microscopic dispersion has even better characteristics. Its response can be compared to the behavior of some other modified binders characterized with this same method.

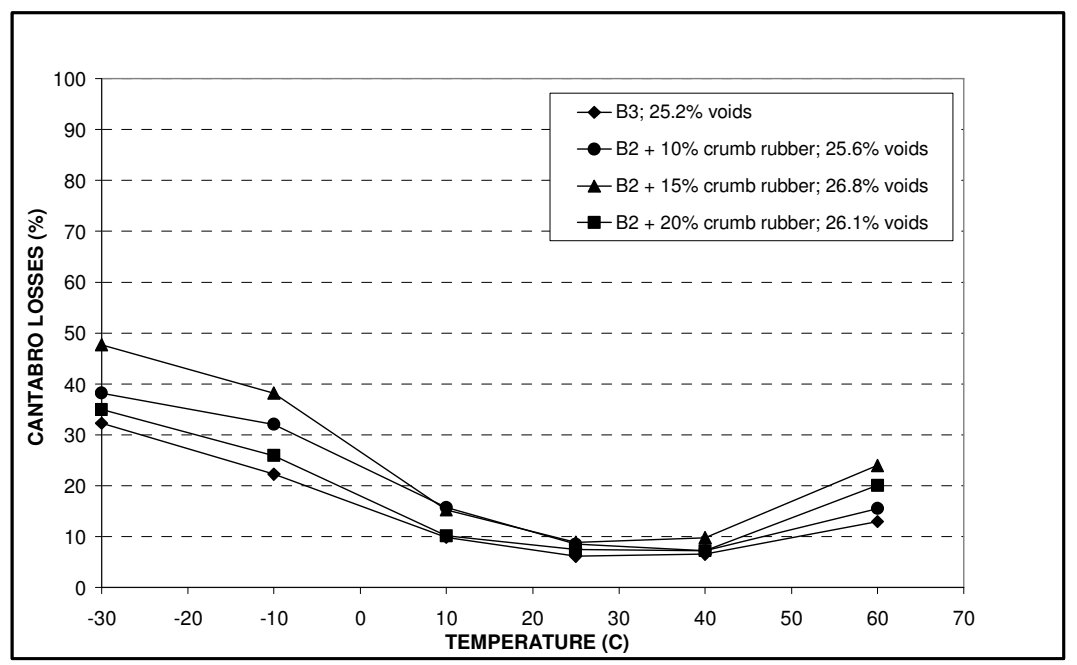

Figure 5. UCL Performance curves. B2 and B3 binders. Wet procedure

\section{Conclusions}


The results of the evaluation of the crumb rubber effect are summarized as follow:

Dry procedure without digestion: The mixtures manufactured with crumb rubber have a lower compaction. It looks as if the thickness of the bitumen film which covers the aggregates is higher, increasing the distance between coarse aggregates and decreasing the mixture compaction. The mastic manufactured following this procedure has a lower cohesion capacity than the original binder, producing higher Cantabrian losses.

Dry procedure with digestion: When the mixture is manufactured using the dry procedure and maintained for 1 or 2 hours at $165^{\circ} \mathrm{C}$, there is an effect on the binder cohesion ability, although the compactability remains the same. The Cantabrian losses for the mixtures manufactured with binders and crumb rubber decrease, but they keep a high porosity, similar to that of the mixtures manufactured without digestion.

Wet procedure: The crumb rubber effect is more favorable when it is added following the wet procedure. Both the binders manufactured in the lab by stirring and the binder manufactured by microscopic dispersion, show higher cohesion ability than the original binders. These bitumens have also good workability and handling conditions. The mixtures manufactured using this method have the same compaction than the ones obtained using the original binders.

If the three procedures are compared, dry procedure with and without digestion and wet procedure, the third one presents clear advantages, especially when the binders are manufactured by microscopic dispersion.

\section{References}

Epps J. "Uses of Recycled Rubber Tires in Highways". NCHRP Synthesis 198, TRB, National Research Council, Washington, DC, 1994, 162 pp.

Hicks R.G., Lundy J.R., Lehy R.B., Hanson D., Epps J. "Crumb rubber modifier in asphalt pavement-Summary of practices in Arizona, California and Florida" Report $N^{o}$ FHWASA-95-056- Federal Highway Administration 1995.

Leto M., Salini R. "Study of recycled tyre rubber in asphalt concrete mixtures", Proceedings of the Asphalt Rubber 2000, Vilamoura, Portugal, p. 341-357.

Morris G.R., Scott N.R., “Arizona's Experience with Asphalt Concrete Friction Courses", 59th Annual Meeting AASHTO, Los Angeles, California, 1973.

Pérez Jiménez F., Gordillo J. "Optimization of Porous Mixes Through the Use of Special Binders", Transportation Research Record N $N^{o}$ 1265, Washington, D.C., 1990. p. 59-68.

Pérez Jiménez F., Miró Recasens R. "Characterization procedure of Asphalt Binders with the Cántabro Test. UCL Method", $5^{\text {th }}$ Eurobitume Congress, Stockholm, Volume 1A, 1993, p. 209-213. 
Pérez Jiménez F., Miró Recasens R. "Caractérisation mécanique de liants asphaltiques: méthode UCL", Mechanical Tests for Bituminous Materials, Di Benedetto \& Francken (eds), RILEM 1997, p. 41-46.

Pérez Jiménez F., Miró Recasens R., Martínez, A "Effect of Filler Nature and Content on the Behaviour of Bituminous Mastics", International Journal of Road Materials and Pavement Design, Volume 9, 2008, p. 417-431.

Van Kirk J., Holleran G., "Reduced Thickness Asphalt Rubber Concrete Leads to Cost Effective Pavement Rehabilitation", 1st International Conference World of Pavements Sydney 2000. 